\title{
Escolha do curso por prounistas: estudando a dimensão subjetiva da desigualdade
}

\author{
Alessandra dos Santos Oliveira \\ Faculdades Metropolitanas Unidas - São Paulo - SP - Brasil \\ Ana Mercês Bahia Bock \\ Pontifícia Universidade Católica de São Paulo - São Paulo - SP - Brasil
}

\begin{abstract}
Resumo
Este artigo tem em sua base uma pesquisa realizada sobre a escolha do curso universitário por bolsistas ProUni e tem como finalidade contribuir para os estudos sobre a dimensão subjetiva da desigualdade social. O pressuposto básico é de que as significações subjetivas, presentes e evidenciadas nesta escolha, são fonte de informação para o debate da desigualdade social, na medida em que estes estudantes têm necessariamente origem em segmentos pobres da população e alcançaram a universidade. Foram entrevistados estudantes bolsistas de cursos com clientelas de diferentes perfis em uma mesma universidade. Os resultados são o conteúdo deste artigo, onde se destaca o sentimento de vitória pela conquista da universidade e o projeto de ultrapassar o que suas famílias já conquistaram, tornando-se melhores. A reflexão sobre como estes projetos estão significados pelos estudantes bolsistas permite contribuir para os estudos sobre a dimensão subjetiva da desigualdade social no Brasil.
\end{abstract}

Palavras-chave: Educação; igualdade social; subjetividade.

\section{Choose the course by prounistas: studying the subjective dimension of inequality}

\begin{abstract}
This article is based on a survey about the choice of university course by ProUni fellows and aims to contribute to the studies on the subjective dimension of social inequality. The basic assumption is that the subjective meanings, present and discussed in this choice, are a source of information for the discussion of social inequality, to the extent that these students have necessarily from poor segments of the population and reached the university. Scholarship students were interviewed courses with clienteles of different profiles in the same university. The results are the contents of this article, which highlights the feeling of victory by winning the university and the project beyond what their families have won, becoming better. Reflection on how these projects are meant for scholarship students allows contribute to studies on the subjective dimension of social inequality in Brazil.
\end{abstract}

Keywords: Education; social equality; subjectivity

\section{Elección de curso por becarios: estudiando la dimensión subjetiva de la desigualdad}

\begin{abstract}
Resumen
Este artículo tiene en su base una investigación realizada sobre la elección del curso universitario por becarios ProUni y tiene como finalidad contribuir para los estudios sobre la dimensión subjetiva de la desigualdad social. El presupuesto básico es que las significaciones subjetivas, presentes y evidenciadas en esta elección, son fuente de información para el debate de la desigualdad social, en la medida en que estos estudiantes tienen necesariamente origen en segmentos pobres de la populación y alcanzaron la universidad. Se entrevistaron estudiantes becarios de cursos con clientelas de diferentes perfiles en una misma universidad. Los resultados son el contenido de este artículo, en que se destaca el sentimiento de vitoria por la conquista de la universidad y el proyecto de ultrapasar lo que sus familias ya conquistaron, volviéndose mejores. La reflexión sobre cómo estos proyectos están significados por los estudiantes becarios permite contribuir para los estudios sobre la dimensión subjetiva de la desigualdad social en Brasil.
\end{abstract}

Palabras clave: Educación; igualdad social; subjetividad. 


\section{Introdução}

O presente artigo é fruto de pesquisa ${ }^{1}$, cujos objetivos foram investigar o processo de escolha profissional de jovens universitários da camada pobre, visando contribuir para os estudos sobre a dimensão subjetiva da desigualdade social.

Ao propormos o estudo da dimensão subjetiva da desigualdade social, levamos em consideração que esse fenômeno social não é constituído somente de uma dimensão objetiva, que se refere às desigualdades na distribuição de renda que marcam as relações sociais existentes a partir do sistema capitalista. Consideramos que a desigualdade da sociedade é caracterizada também por uma dimensão que é subjetiva, constituída por aspectos psicológicos; sendo assim, este artigo busca contribuir com a produção de conhecimentos sobre como os jovens pobres vivenciam subjetivamente o processo de escolha de um curso universitário, acreditando que esta compreensão nos permita analisar a dimensão subjetiva da desigualdade que, presente em nossa sociedade, marca e constitui todos os processos e relações que nela se dão.

Até os anos 2000, o acesso dos jovens pobres ao ensino superior era quase inexistente e, após esse período, houve uma expansão na oferta de vagas devido a novas políticas econômicas e sociais que ampliaram o acesso dos jovens de baixa renda à universidade, gerando uma maior demanda (ainda restrita) desta classe social para uma profissionalização a partir de um curso superior. Essa nova realidade gerou a necessidade de se compreender e conhecer melhor o processo de escolha e a inserção destes jovens na universidade, lugar, até então, ocupado somente ou prioritariamente pelos segmentos mais ricos da sociedade. É pressuposto, neste estudo, que a escolha do curso universitário pelos jovens pobres ocorre em condições sociais desiguais às dos jovens de outras camadas mais ricas, sendo relevante a ampliação de estudos que busquem dar visibilidade a tal fato. Dentre os aspectos que nos parecem distinguir as escolhas dos diferentes jovens, escolhemos aqui enfatizar e pesquisar a dimensão subjetiva deste fenômeno, ou seja, os significados, valores, sentimentos que acompanham e fazem parte deste processo de escolha.

Nessa perspectiva, Ristoff (2011) pontua que a palavra que marca esta década é democratizar e "isso significa criar oportunidades para que os filhos dos milhares de jovens de classe baixa, pobres, filhos de classes trabalhadoras e estudantes das escolas públicas tenham acesso à educação superior" (p. 208).

Dentro deste cenário, o Programa Universidade Para Todos - ProUni, foi criado no contexto das novas políticas de acesso à Educação Superior pelo Governo Federal pela

\footnotetext{
1 A pesquisa mencionada foi realizada a título de doutoramento no Programa de Pós-Graduação em Educação: Psicologia da Educação, em 2014. Intitulada a "Dimensão Subjetiva da Desigualdade Social: um estudo sobre a escolha do curso universitário entre os alunos bolsistas do Programa Universidade Para Todos - ProUni" (Oliveira, 2014).
}

MP $n^{\circ} 213 \backslash 2004$ e institucionalizado pela Lei $n^{\circ} 11.096$, em 13 de janeiro de 2005, visando oferecer bolsas de estudo integrais e parciais em cursos de graduação em instituições privadas de educação superior. "Criado pelo Governo Federal e institucionalizado pela Lei 11.096 de 13 de janeiro de 2005, oferece em contrapartida, isenção de alguns tributos àquelas instituições de ensino que aderem ao Programa" (http://prouniportal.mec.gov.br/.).

Em 2008, o Instituto Nacional de Estudos e Pesquisas Educacionais Anísio Teixeira ([INEP], 2008) apresentou uma pesquisa com internautas e alunos que responderam ao questionário socioeconômico do Exame Nacional do Ensino Médio - Enem, com o objetivo de revelar o que motivou o aluno a realizar o exame e apontou que o interesse da maioria era a inserção na Educação Superior. O site do INEP divulgou os seguintes dados: "dentre os motivos alegados para realizarem o Enem, o mais apontado foi entrar na faculdade $(72,23 \%)$, seguido de testar conhecimentos e capacidades de raciocínio $(16,72 \%)$ e conseguir um bom emprego ou saber se está preparado para o futuro profissional $(10,61 \%)$ ".

Nosso estudo se propôs a compreender a dimensão subjetiva do processo de escolha do curso superior pela camada pobre, fenômeno ampliado por esta nova política, entendendo que os aspectos aqui conhecidos permitem contribuir com os estudos sobre a dimensão subjetiva da desigualdade social.

Gonçalves e Bock (2009) afirmam que a análise dos fenômenos sociais permite desvendar um processo do qual resultam produtos, objetivos e subjetivos. A dimensão subjetiva pode ser reconhecida em produções diversas. "São produtos coletivos, nos quais se percebe a participação de participantes e a presença de subjetividades, ou seja, uma dimensão da realidade" (p. 145).

Ao estudarmos as escolhas da profissão deste segmento social, buscamos dar visibilidade à historicidade e às mediações que atravessam sua existência, considerando que essas são, ao mesmo tempo, construções individuais e sociais. Nesse sentido, Aguiar e Ozella (2006) afirmam "a compreensão do homem se dá pela busca da gênese social do individual, se quisermos apreender o processo de escoIha, temos que focar as mediações sociais e históricas constitutivas de tal processo e observar como o sujeito configura tais determinações" (p.14). Os autores ainda enfatizam que a discussão sobre a escolha deve ser "situada na trama de um debate que considere o histórico, o social, o ideológico e o subjetivo como elementos, ao mesmo tempo, diferenciados e inseparáveis" (p.14).

A dimensão subjetiva se situa, assim, nos âmbitos individual e social, que não podem ser considerados de forma isolada; é a dimensão do sujeito, que é visto como parte ativa na construção dos fenômenos sociais e que constitui, a partir desta participação, sentidos e significados que passam a compor o fenômeno.

Segundo Gonçalves e Bock (2009), a visão sócio-histórica considera a complexidade do fenômeno, que inclui uma dimensão subjetiva "na qual se imbricam aspectos subjetivos individuais que constituem os fenômenos sociais, aspectos 
objetivos dos quais se apropriam os indivíduos e que constituem sua subjetividade; e aspectos subjetivos que já estão incorporados à objetividade e dela fazem parte" (p. 151-152).

Dessa forma, a escolha da profissão, por alunos bolsistas ProUni, tem a ver com a desigualdade social. A escolha profissional, sob a ótica da psicologia sócio-histórica é tomada como uma atividade realizada pelos sujeitos, em uma sociedade marcada pela desigualdade social, que marca, por sua vez, a vivência desta escolha pelos diferentes ou desiguais sujeitos da sociedade.

Alguns estudos, como os de Aguiar e Ozella (2003), Bock (2002, 2008), Oliveira (2009) e Abdal e Navarra (2014) colaboram para a compreensão da vivência da escolha por jovens que têm condições desiguais de acesso à educação e de possibilidades de escolha de um curso superior. Saraiva e Nunes (2011), Amaral e Oliveira (2011) e Monguim (2015) colaboram pesquisando e indicando aspectos da trajetória destes jovens bolsistas no decorrer do curso superior.

Aguiar e Ozella (2003), em pesquisa realizada com jovens de classes populares concluíram que, muitas vezes, o jovem vivencia o processo de escolha impregnado por valores liberais que ocultam a realidade e colaboram para que o indivíduo acredite que a escolha depende apenas dele. As consequências desse processo podem levar o jovem à culpabilização do fracasso profissional e à compreensão reducionista de que o sucesso conquistado resulta apenas de seu empenho e esforço.

Bock (2008) estudou em sua tese de doutorado a orientação profissional destinada às classes pobres e, ao analisar a fala de um dos participantes, afirma que ele "... divide o mundo e as pessoas entre aqueles que "conseguem" e "aqueles que não conseguem" (p. 132), e se coloca exatamente a questão, se vai também 'conseguir'. Seus receios se relacionam aos desafios que acha que deve superar para conseguir. Demonstra o sentimento de medo de não conseguir, pois sabe que existem muitos obstáculos para serem ultrapassados e que são diferentes dos das pessoas de classe média e alta.

Oliveira (2009) também constatou que a escolarização (que envolve a escolha profissional) é vista como "relacionada a uma condição de vida melhor e parece que essa possibilidade depende necessariamente do esforço pessoal para conquistar o curso universitário. A escolarização aparece relacionada a uma melhoria de vida..." (p.104).

Abdal e Navarra (2014) pesquisaram em quais condições as distâncias percorridas na cidade, envolvendo idas e vindas à Instituição de Ensino Superior (IES) constituem um aspecto relevante na tomada de decisão destes jovens, quando buscam o ingresso no ensino superior. Concluem que a proximidade do local de moradia ou do trabalho é um critério utilizado, mas não afirmam ser o de maior importância, pois o "... Ensino Superior como sonho e expectativa de mobilidade social, o fundamental é 'fazer a faculdade', seja ela qual for" (p. 86). Saraiva e Nunes (2011) estudaram a efetividade do Programa Universidade Para Todos (ProUni) a partir da ótica de seus beneficiários. “... grande oportunidade, privilégio ou como vitória, um implícito subentendido de que o programa é valorizado por lhes proporcionar inclusão em um ambiente ao qual não teriam acesso de outra forma" (p.954). Mas os autores destacam que esta inclusão não é vista como direito e sim como dádiva à qual se tem acesso por "sorte".

Amaral e Oliveira (2011) estudaram as trajetórias pessoais e profissionais dos jovens bolsistas ProUni, concluindo que a oportunidade de estar no Ensino Superior pode colaborar para elevar a autoestima destes jovens e proporcionar aumento da renda familiar e elevar as chances de alargamento do capital social. Mongim (2015), ao pesquisar itinerários sociais de estudantes beneficiários do ProUni, aponta o importante papel dos agentes institucionais, incluindo a família, para o desenvolvimento e mobilidade dos jovens estudantes. Alguns aspectos do estudo merecem destaque: a ética da escolarização que permite o estudo mesmo em condições adversas (a ética do sacrifício); a importância da família e sua adesão ao projeto de escolarização de um de seus membros (às vezes o primeiro deles); o diploma de curso superior como necessário à mobilidade social; e a importante constatação da sensação do jovem de que passa a transitar entre dois universos simbólicos diferentes.

O presente estudo pretendeu fazer parte desse conjunto de pesquisas que quiseram ir além dos fatores sociais que marcam a escolha da profissão, como pobreza ou riqueza, para dar visibilidade a aspectos subjetivos que compõem também o cenário da escolha da profissão por jovens com diferentes e desiguais condições sociais.

\section{Método}

A pesquisa realizada foi desenvolvida a partir da perspectiva do materialismo histórico e dialético que enfatiza a compreensão dos fenômenos a partir de sua historicidade e na qual o particular é considerado parte da totalidade social. Também foi marcada pela perspectiva qualitativa de pesquisa.

A escolha da universidade considerou alguns critérios ${ }^{2}$. A escolha dos cursos, onde se buscaria os alunos bolsistas, ocorreu a partir de informações oferecidas pelo setor de vestibular, que possibilitaram a caracterização do perfil socioeconômico daqueles que se inscreveram para o vestibular de verão de 2013. A partir desses dados, localizamos os cursos ${ }^{3}$ que contavam com alunos candidatos com as melhores (Direito e Psicologia) e as piores condições socioeconômicas (Serviço Social e Pedagogia). Escolhemos quatro participantes, bolsistas de cada um destes cursos, cursando o último ano, momento em que se pode tomar o

2 Critérios para escolha da Universidade: ser particular ou filantrópica, ter adesão ao ProUni, ter qualidade em seu desempenho medido pelas avaliações do MEC, apresentar uma organização para o atendimento dos alunos bolsistas, facilitando a identificação destes sem constrangimentos e ter interesse na pesquisa.

3 Os critérios selecionados foram: acesso à internet, ensino fundamental, número de empregados, grau de instrução dos pais, atividade remunerada, trabalho, número de micro computadores na casa, transporte utilizado (ida à PUC) e número de aparelhos de TV em casa. 
processo da escolha realizada com certo distanciamento, apresentando, a nosso ver, melhores condições de elaborar respostas e de avaliar o processo de escolha do curso. Optamos por trazer, para este relato, apenas dois dos participantes que nos pareceram representar o conjunto.

Participante 1: Pedro 4 , aluno bolsista ProUni no curso de Direito, com 23 anos à época da pesquisa. Mãe com ensino superior completo e ocupação de professora; pai também com ensino superior completo com ocupação de corretor de imóveis.

Participante 2: Carlos, aluno bolsista ProUni no curso de Serviço Social, com 24 anos. Mãe com ensino fundamental incompleto trabalhando como diarista e pai também com ensino fundamental incompleto, trabalhando como pedreiro.

Os jovens entrevistados preencheram fichas de identificação que tiveram como objetivo a obtenção de dados pessoais e socioeconômicos dos participantes. Utilizamos a entrevista como um instrumento dialógico (González-Rey, 2005) e a partir delas buscamos acessar, em um processo construtivo-interpretativo, as significações dos sujeitos que caracterizam suas escolhas por um curso universitário em uma sociedade marcada pela desigualdade social. O projeto de pesquisa foi aprovado pela Comissão de Ética da Universidade com parecer número 569.621.

A partir das entrevistas realizadas, analisamos a fala dos jovens como forma de avançar na compreensão de seus sentidos. Para tanto, foi utilizado como instrumento de análise o procedimento dos Núcleos de Significação, proposto por Aguiar e Ozella (2006). A constituição dos núcleos de significação se refere a um processo de articulação de conteúdos das falas, quando são, inicialmente, construídos pré-indicadores e indicadores de significações, sendo os núcleos o final da organização da fala, como expressão dos sentidos. De acordo com Aguiar e Ozella (2006), o critério para se chegar aos núcleos de significação é que eles devem "expressar os pontos centrais e fundamentais que trazem implicações para o sujeito, que o envolvem emocionalmente, que revelam as determinações constitutivas do sujeito". (p.235).

A seguir, apresentamos os núcleos de significação ${ }^{5}$, acompanhados de uma síntese de cada participante. Os trechos do texto retirados de suas falas aparecem em itálico, permitindo uma aproximação maior do leitor com as falas dos participantes e a compreensão dos núcleos.

\section{Resultados}

\section{Núcleos de Significação Pedro - Direito:}

1. Eu era um pobre privilegiado; 2 . Tinha vontade de ser professor; 3. Eu tinha consciência sobre o que era impor-

\footnotetext{
4 A fim de preservar a identidade dos entrevistados os nomes mencionados são fictícios.

5 É importante destacar que os títulos dos Núcleos de Significação apresentados, foram retirados a partir das falas dos participantes da nossa pesquisa.
}

tante para mim; 4. Minha tia é bem sucedida financeiramente; 5 . Não queria me formar em qualquer lugar; 6.Tive uma trajetória acadêmica satisfatória; 7.Tinha uma visão muito limitada das profissões; 8. Com a bolsa aproveitei o curso da melhor forma possível; 9. Me sentia humilhado; 10. Espero ter uma carreira brilhante!

O jovem do curso de direito destaca que nunca passou necessidades e diz: “... sempre tivemos dinheiro para ter uma vida digna. Nós nunca fomos tão poooobres assim, pois sempre tivemos uma vida digna, temos imóvel próprio, um apartamento pequeno na zona sul, dois carros... era um pobre privilegiado". Pedro ressalta que após a morte de seu irmão mais novo, seus pais passam a investir de maneira mais intensa em sua formação:

Aos poucos, fui montando minha própria biblioteca e tinha orgulho disso! Nunca faltou nada em relação aos materiais didáticos, eles faziam questão de investir na minha educação... que eu tivesse uma educação de qualidade. A partir disso, posso dizer que acabei tendo uma grande estimulação intelectual.

Por fim, menciona: “... meus pais sempre me acompanhavam nas tarefas escolares e me ajudavam nas dificuldades que eu podia ter. Mas, minha mãe me acompanhava mais, porque sempre teve mais paciência e mais tempo para me ensinar". Durante sua formação, teve oportunidade de fazer vários cursos, cursinho preparatório para o vestibular, investir em livros e materiais didáticos diversos. Outro aspecto relevante destacado se refere ao fato de que sempre pôde contar com o acompanhamento familiar na realização das atividades escolares. Este aspecto, também apontado por Mongim (2015), reforça a idéia da importância do projeto de estudo ser coletivo na família.

O jovem afirma que sempre teve uma relação satisfatória com os pais, mas que sua mãe o influenciou (principalmente na infância) de maneira mais consistente. Esse aspecto fica explícito quando menciona o fato de que queria ser professor.

Na minha infância ela [a mãe] me influenciou muito... tinha vontade de ser professor, porque minha mãe sempre foi um exemplo pra mim por ter vocação, talento e gostar do que faz. ... Aos poucos, descobri que tinha uma visão romântica e distorcida sobre a profissão de professor e fui percebendo que não era isso que queria para o meu futuro.

Apesar de considerar que as condições de vida foram relevantes para sua formação e reconhecer que teve oportunidades de estudo que muitos de seus colegas não tiveram, também valoriza aspectos individuais, quando afirma:

sempre fui disciplinado e responsável. O fato de ter criado o hábito de ler logo cedo, facilitou muito na minha trajetória escolar. Desde cedo, eu lia porque gostava, sentia prazer... Meus pais me estimulavam quanto aos estudos, mas eu me dedicava e me esforçava sem a necessidade da pressão ou 
cobrança por parte deles, porque eu tinha consciência sobre o que era importante para mim.

Valoriza e relaciona vários aspectos, que indica como pessoais, ao seu sucesso profissional, como, por exemplo, disciplina, responsabilidade e esforço, entendendo-os como fundamentais para a conquista do seu objetivo acadêmico.

Outro aspecto relevante que se relaciona a sua escoIha profissional se refere ao fato do jovem afirmar que:

Além dos meus pais também tenho uma tia... que fez um curso superior, ela fez direito ... Ela atua na área, em um escritório de advocacia e foi uma das minhas maiores motivações para fazer direito... Então, minha tia é um exemplo para mim, porque ela é bem sucedida financeiramente... Passei a ter cada vez mais orgulho dela, pois era pobre e hoje vive de forma confortável.

A vida confortável da tia, advogada, surge em sua fala como aspecto marcante na escolha da profissão. $O$ fato de a tia ser bem sucedida financeiramente aparece em contraposição à visão da carreira de professor, visão esta que considerou romântica.

A escolha da instituição universitária foi também importante. Sobre isso, ele diz:

... Não queria entrar em qualquer instituição de ensino, queria me formar em uma faculdade de renome, pois sabia que isto é considerado no mercado de trabalho, na seleção de um emprego, enfim, não queria me formar em qualquer lugar! ... Eu sabia que não estava concorrendo com outros jovens em pé de igualdade, porque muitos tinham estudado nas melhores escolas, se preparado nos melhores cursinhos...

A busca por um curso em uma faculdade com reconhecimento mostra a preocupação de Pedro com seu futuro profissional, indicando as dificuldades que os mais pobres têm de concorrerem para vagas em cursos mais bem avaliados. As condições para escolha e ingresso nos cursos são vistas como distintas, o que seria aspecto importante na construção da carreira profissional futura.

Em relação a sua trajetória escolar, só descreveu lembranças positivas, pois nunca teve problemas, teve excelentes professores e sempre teve boas relações na escola. Ele diz: "... Tive sorte, uma trajetória acadêmica satisfatória com excelentes professores que contribuíram para que eu conseguisse chegar até aqui... Acho que isso se deve ao fato que era um bom aluno, não tinha problemas de aprendizagem e não dava trabalho". Observamos que ao mesmo tempo em que considera sorte o fato de ter tido excelentes professores e uma formação satisfatória, também considera que isso se deve ao fato de ter sido um bom aluno. O jovem acredita que sua postura fez muita diferença em sua trajetória escolar, pois possibilitou que concluísse os estudos de forma satisfatória.

Em relação à conquista da bolsa ProUni o jovem afirma: se não conseguisse a bolsa, talvez precisasse trabalhar e estudar ao mesmo tempo. Talvez o meu aproveitamento não fosse o mesmo no curso. Então, a bolsa me deu condições de aproveitar o curso da melhor forma possível... Hoje posso dizer que a bolsa permitiu que eu construísse uma formação acadêmica mais sólida e consistente...

Em sua fala, expressa que a bolsa ProUni foi uma importante conquista, pois permitiu um melhor aproveitamento e investimento em sua formação acadêmica.

Para Pedro, a vivência acadêmica inicial não foi fácil, pois a maioria de seus colegas possui condição social mais privilegiada. Sobre isso, o jovem ressalta:

No começo isso me envergonhava, me sentia humilhado com alguns comentários deles. Eu tinha vergonha de assumir que minha mãe é professora e que sou bolsista ProUni. Pela primeira vez me senti humilhado, sentia vergonha de me expor, de perguntar... Então, a convivência inicial foi delicada, me sentia muito inferiorizado e sentia que o tempo todo era lembrado da minha condição de filho de assalariado. O curso de direito é muito elitizado... Enfim, eles têm uma condição de vida muito distante da minha.

Sentia-se humilhado e envergonhado, por não ter as mesmas condições financeiras que a maioria de seus colegas. A solução encontrada, para se sentir mais à vontade no ambiente acadêmico, foi a de buscar aproximação de pessoas que também compartilham vivências semelhantes a sua.

Em sua fala o jovem informa sobre os aspectos que contribuíram para a sua escolha profissional:

... cheguei à conclusão que queria exercer uma profissão que me desse mais do que condições dignas de vida, queria status e principalmente me sentir mais valorizado socialmente. Eu não sentia orgulho das profissões dos meus pais e queria ser diferente. Em relação a minha escolha, era fundamental ter prestígio e um retorno financeiro satisfatório. Na verdade, sempre tive pavor de exercer uma profissão que sentisse vergonha e me sentisse humilhado!

Status, valorização social, retorno financeiro voltam a estar presentes, na fala de Pedro, como meta da profissionalização. Também menciona a vontade de realizar um trabalho em prol da comunidade, mas a partir de sua fala, não especifica que tipo de trabalho poderia fazer e nos indica que esse projeto ficará para segundo plano em sua atuação profissional.

\section{Núcleos de Significação Carlos - Serviço Social:}

1. A gente passou muitas dificuldades; 2. Ainda pequeno adorava quando ganhava livros; 3 . Eu precisava passar de ano de qualquer jeito; 4. O sonho da minha mãe foi o de ver os filhos formados; 5 . Ninguém na minha família conseguiu terminar os estudos; 6 . Sabia que sozinho não daria 
conta; 7. O trabalho começou a me atrapalhar nos estudos; 8. Dependeria do meu esforço levar adiante meus estudos; 9. A injustiça social sempre mexeu comigo; 10. O ProUni foi uma das melhores coisas que aconteceu na minha vida.

Carlos apresenta diversas dificuldades que enfrentou quando pequeno e que Ihe causaram sofrimento. Ele afirma:

... minha mãe ficou viúva quando eu tinha 8 anos. Lembro que foi um sofrimento grande pra gente... Daí, a minha mãe que é diarista... teve que assumir a responsabilidade da família, pagar as contas de casa, ela assumiu tudo com muita dificuldade. A gente passou muitas dificuldades, porque a minha mãe ganhava pouco e trabalhava pra sustentar a gente.

Carlos relata diversos sentimentos positivos em relação à escola: "Eu lembro que como minha mãe trabalhava em várias casas, sempre ganhava muitas coisas, a gente ganhava roupas, brinquedos, livros...". Ainda pequeno adorava quando ganhava livros. A família de Carlos sempre conviveu com muitas dificuldades financeiras, contando com as doações das famílias para as quais a mãe dele trabalhava.

O jovem destaca que foi o primeiro da família a chegar ao ensino superior e que a mãe teve um papel fundamental nessa conquista. Ele afirma:

O sonho da minha mãe sempre foi o de ver os filhos formados, com curso superior. Minha mãe cobrava de mim que não parasse de estudar... sempre foi importante que seus filhos estudassem ... Ela queria que a gente tivesse um futuro melhor do que o que ela teve... Ela foi fundamental para que eu chegar aonde cheguei.

Observamos que o projeto e insistência da mãe tiveram um papel fundamental na sua trajetória escolar. Novamente o aspecto do apoio da família surge como importante no processo, fortalecendo conclusões dos estudos anteriores aqui citados.

Em relação a sua vivência na escola Carlos menciona:

... em época de prova, sempre estudava bastante porque já tinha ficado para recuperação e sabia como era chato... Então, eu gostava de aprender, mas em época de prova eu me preocupava em estudar pra passar de ano. Isso era o mais importante, pra mim e pra minha mãe também...

Carlos disse que sempre estudou em escola pública e que durante uma época estudava para passar de ano, tendo como uma das motivações a de não decepcionar sua mãe.

Carlos tinha o sonho de fazer uma faculdade e se orgulha do fato de ter conseguido "chegar lá" como podemos observar em sua fala:

... eu já conquistei muito, me sinto privilegiado, porque já ultrapassei muito o que minha familia conquistou ... Ninguém na minha família, nem meus primos e tios que não moram aqui, conseguiu terminar os estudos. Você sabe o que isso significa? (tempo) Eu penso que o fato de ter uma condição melhor do que a que meus pais tiveram já é uma conquista e um orgulho pra mim. Sinto que meu irmão está mudando, está me vendo como um exemplo em casa e aos poucos está pensando mais no futuro, pensando em voltar a estudar... Isso é muito bom pra mim!

Dessa forma, o jovem se sente privilegiado, por ter alcançado uma condição melhor do que a que seus pais alcançaram.

Em sua trajetória escolar, Carlos reconhece que teve "ajudas" primordiais que contribuíram para que conseguisse prosseguir em seus estudos. O jovem relata: "Mas, eu sabia que sozinho não daria conta e que voltaria a me desmotivar...". Assim, como reconhece que sua mãe foi fundamental para que continuasse seus estudos, também percebe a importância de alguns amigos que o auxiliaram a superar obstáculos nesse contexto.

O jovem que começou a trabalhar aos quatorze anos e foi

... percebendo que o trabalho começou a me atrapalhar nos estudos, não conseguia me concentrar nas aulas, fui ficando cada vez mais cansado e acabei reprovando no final do último ano do ensino médio ... muitas vezes sentia que estava presente apenas fisicamente na sala de aula. Sentia que o prazer em aprender que já não era muito, tinha se esgotado com o meu cansaço.

Assim, como a maioria dos jovens de sua classe social, ressaltou que precisou trabalhar e estudar ao mesmo tempo.

O jovem valoriza aspectos pessoais como, por exemplo, esforço, persistência e disciplina que contribuíram para que alcançasse seu objetivo. Ele diz:

acho que foi importante planejar uma rotina de estudo e isso só consegui com disciplina mesmo... Acho que chegou uma hora que caiu a ficha que dependeria de mim mesmo, do meu esforço conseguir levar adiante meus estudos e fazer mais do que meus pais e meu irmão conseguiram, foi acreditar nisso que me impulsionou, me levou pra frente e que me fez vencer! ... eu não tive o privilégio de ter uma família que me ajudasse financeiramente, eu tive que correr atrás das oportunidades, né?

Dessa forma, expressa o sentimento de orgulho por ter, a partir do esforço individual, conseguido chegar ao curso superior. Esse aspecto corrobora estudos que indicam a naturalização do processo de ingresso no ensino superior e a idéia de que esse ingresso não é um direito e sim uma dádiva ou o resultado do esforço pessoal. Aguiar e Ozella (2003), Bock (2002, 2008), Oliveira (2009) e Saraiva e Nunes (2011) trazem tais aspectos como conclusões importantes de seus estudos.

Em relação a sua inserção na universidade e como significa a escolha da profissão realizada, Carlos afirma: 
Essa oportunidade me fez conhecer uma profissão pela qual fiquei encantado: serviço social. Durante a palestra da profissional... percebi que o assistente social, pode oferecer um trabalho para pessoas vulneráveis e colaborar para a inclusão delas na sociedade... Enfim, depois de tudo, me decidi mesmo pelo curso de serviço social. Sabia que não ia ganhar um salariãooo, assim como nas outras profissões que tinha pensado, mas era o que eu queria fazer e pra mim... mais importante que o dinheiro numa profissão é a satisfação de estar realizando um trabalho que contribua com a conquista de uma sociedade mais justa, mais humana, menos desigual.

Dessa forma, ao conhecer a profissão de serviço social percebe que pode trabalhar em prol de melhores condições sociais.

Os motivos da escolha de sua profissão relacionam-se ao fato de poder desenvolver um papel social que contribua com a diminuição da desigualdade. Em sua fala destaca:

O fato de ser pobre me deu uma compreensão diferente dos jovens de outras classes sociais, pois vivenciei e vivo na pele as consequências da desigualdade e isto me deixa indignado e com vontade de usar a profissão que escolhi para fazer alguma coisa pra melhorar as condições das pessoas que sofrem com a injustiça social.

O jovem tem consciência da desigualdade e sonha com a igualdade das condições sociais em que vive. $\mathrm{O}$ curso escolhido the deu uma leitura diferente da realidade mais crítica e consciente, sendo esta formação, importante para a atuação que o jovem quer adotar em seu cotidiano profissional. Ele diz:

Mas hoje no final da faculdade, posso te dizer que como assistente social, pretendo colaborar para que as pessoas mais vulneráveis socialmente tenham condições melhores de vida ... E não queria trabalhar só pra mim, pra ganhar o meu dinheiro, entende?

Por fim, é importante destacar que a escolha do curso, também é uma forma de retribuição social, visto que a partir de sua atuação o jovem pretende contribuir com a redução da desigualdade e injustiça social. Esta nossa conclusão pode se ancorar nos aspectos pesquisados por Mongim (2015) que aponta como desafio para estes jovens a inserção em dois universos: o da faculdade e o universo social de origem, “... a posição de viver no limiar entre dois universos sociais distintos pode representar, ao mesmo tempo, satisfação pelos desafios superados, como também certo sentimento de solidão decorrente de uma ruptura com o universo familiar ou dos amigos." (p.940).

Em relação à conquista da bolsa do ProUni, o jovem afirma:

Eu tinha consciência de que só poderia dar continuidade nos estudos se conseguisse uma bolsa, pois não tinha condições pra isso... Quando consegui a bolsa ProUni, foi outra vitória, parecia que tinha ganhado na megasena acumulada. Posso dizer que o ProUni, foi até hoje uma das melhores coisas que aconteceu na minha vida.

Mongim (2015) traz aspectos que enriquecem esta conclusão, pois indica que o curso superior "parece representar a autorização necessária para o estudante se apresentar como alguém dotado de conhecimentos específicos capazes de tornar possível a mudança da posição de trabaIhador subordinado para a de trabalhador especializado e com mais autonomia" (p.936).

\section{Discussão}

Destacamos que os jovens relacionaram a conquista do curso universitário a aspectos individuais e meritocráticos, como também constataram Aguiar e Ozella (2003), Bock, S.(2008) e Oliveira (2009). Entretanto, a continuidade de seus estudos também está associada a outras pessoas (pais, amigos, tios, dentre outros) que lhes foram fundamentais na trajetória escolar. Observamos que a ideia de "venci, porque me esforcei", se soma à ideia de "se não fosse o apoio, não teria vencido". O destaque na fala para o esforço próprio é significativo, sendo, no entanto, distinto entre os dois participantes.

Não há nas falas a afirmação de um Estado que busca políticas de inclusão. Não há, nas falas, a ideia de direitos. Aparecem as queixas da escola pública, vista como uma escola de baixa qualidade e as dificuldades geradas pela concomitância do trabalho com o estudo, que aparecem como fatalidade, pelo fato de serem pobres. Não há nas histórias contadas momentos de reivindicação, de luta coletiva, de exigência de direitos. A Bolsa ProUni aparece como "caída do céu". Isto corrobora conclusões de Mongim (2015) em que os alunos afirmam ser a bolsa uma dádiva.

A preocupação em ter uma profissão que ajude a transformar a realidade da pobreza e que possa ser de ajuda às pessoas menos assistidas pelo Estado ou pela sorte aparece apenas para o bolsista do curso de Serviço Social. O jovem do Direito apresenta preocupações mais relacionadas ao seu sucesso profissional, ao reconhecimento social ou aos desejos pessoais de realização. Poderíamos indicar, como possibilidade de compreensão, a ideia de que os jovens "menos pobres"6 apresentam uma aproximação maior com os valores das camadas mais altas do que os jovens "mais pobres". É importante lembrar que são alunos de último ano dos cursos, o que significa que estão expostos aos valores dominantes do segmento social que frequenta os cursos há, pelo menos, quatro anos. O curso de Serviço

6 É importante notar que não fizemos em nosso estudo uma análise das diferentes condições financeiras e culturais que as famílias de nossos participantes por ventura possuam, por isso as palavras menos pobre e mais pobre aparecem entre aspas. Pelas diferenças de nível de escolaridade e profissões dos pais e outros membros da família, parece haver essa diferença, mas segue entre aspas pela imprecisão que pode conter. 
Social não só recebe alunos de segmentos mais pobres da sociedade, como cultiva valores mais coletivos e de transformação social da desigualdade. Essa condição manteria nosso jovem bolsista mais afastado do que chamamos, aqui, de "contaminação"7. Ao contrário, o jovem do curso de Direito teria, nestes quatro anos, contato maior com os valores e significações de uma camada mais rica que cursa aquela carreira, apropriando-se deles.

Os jovens de nossa pesquisa avançaram em relação à escolaridade dos seus pais, mesmo aquele que já possuía familiares com nível universitário. Isto nos permite compreender o fortalecimento das ideias de vitória e esforço pessoal. É compreensível que, em uma sociedade que utiliza o nível de escolarização como aspecto de distinção entre as pessoas, esses jovens se sintam vitoriosos. Ao analisarem estes processos e, ao fazerem isto com ênfase em visões individualizadoras e naturalizantes, creditam para si e seus familiares a vitória.

Há na fala desses jovens o sentimento de "mudar de lugar" com a entrada na faculdade. Acreditam (principalmente o estudante de direito) que terão condições melhores de vida com a formação universitária. Parece que essa melhora de vida não aparece apenas como melhores condições financeiras e de consumo, mas como uma mudança de "personalidade", de "identidade"; os participantes indicam a possibilidade de serem diferentes do que eram até então, melhorando. Essa melhora parece estar relacionada à aproximação com valores e hábitos da elite dominante.

Pedro (Direito) traz em sua fala uma preocupação acentuada com o retorno financeiro que sua atuação profissional poderá oferecer. Em nossa análise, constatamos que os sentidos da escolha do curso universitário do jovem têm relação direta com as condições propagadas pela ideologia dominante, ou seja, existe a valorização pelo retorno individual, financeiro, status e prestígio. Carlos (Serviço Social) enfatiza a retribuição à sua camada social que acredita poder oferecer com sua formação superior.

Os entrevistados mencionam que a conquista da bolsa ProUni foi importante para a realização do curso universitário. Os jovens entendem esta política como positiva, por oferecer possibilidades para a concretização de um projeto de futuro melhor. Oliveira (2009), Amaral e Oliveira (2011) e Saraiva e Nunes (2011) já se referiam a este aspecto. Acrescente-se aqui, o Estado que, acreditam, deveria investir no ensino superior das universidades públicas, criando condições de fato igualitárias de acesso a esse nível de ensino. Não desenvolvem a análise sobre o ProUni e não o inserem em um programa de governo ou em uma visão de Estado democrático. Uma fala, a de Pedro, exterior à sua vivência, mas necessária para o compartilhamento no espaço universitário; outra fala, a de Carlos, cheia de vida e de cotidiano, mas esvaziada de análise política.

7 Análises no campo do marxismo indicam a apropriação pelos participantes de valores que não são de sua classe social, mas da classe dominante. Ousamos utilizar, em um momento final de conclusões, o termo contaminação para indicar essa apropriação de valores de outra classe social.
Há, na fala dos entrevistados, a presença de sentimentos de humilhação social (vergonha, raiva, divida, inferioridade, incapacidade, dentre outros) expressos a partir das condições de vida e das experiências vividas marcadas pela desigualdade. Os jovens apresentam esses sentimentos (Gonçalves Filho, 1998), pois expressam e avaliam suas experiências utilizando o outro (o rico) como referência; ainda mencionam o quanto se sentem cobrados por estarem ali e que se sentem fora dos padrões da maioria do contexto em que estão inseridos. O acesso ao ensino superior, mesmo que numa universidade conceituada, como ocorre no caso dos entrevistados, não leva à isenção de sentimentos de humilhação, pois, apesar de o ProUni oferecer melhores oportunidades para que os jovens consigam cursar uma universidade, também contribui para a sua existência, na medida em que são vistos como aqueles que necessitam dessa política pública para estar na universidade. Tomam, na realidade, como favor, como também nos ensina Gonçalves Filho (1998) sobre as formas do sentimento de humilhação social.

E uma nova contradição pode ser apontada: sentem-se em outro lugar social, um lugar superior. Significam esta nova situação como uma vitória. Ao mesmo tempo sentem vergonha de sua condição social de origem, significando-a como inferior.

Parecem resolver esta contradição de forma diversa: Carlos traz em suas falas o pertencimento à camada pobre da população, acreditando que o fato de ter conseguido sair deste lugar social lhe permitirá se colocar no lugar dessas pessoas, ser porta-voz e contribuir com a transformação social. Como profissional, afirma então que pretende desenvolver um trabalho social, valorizar a luta pelos direitos e assumir uma postura de "luta" em prol dos direitos sociais adquiridos. Pedro traz em suas falas a identificação com a tia que, como ele, saiu daquele lugar social. Pretende trabalhar com ela, recebendo contribuições financeiras que Ihe permitam uma vida melhor. Seu projeto é mais para si mesmo, deixando para trás a pobreza e a vergonha.

A partir do exposto observamos que a perversa desigualdade social cria sentimentos de gratidão e projetos de ajuda e compromisso com a transformação da sociedade para aquele que não se distanciou muito da própria condição de pobreza, mas cria sentimentos de vitória e projetos de enriquecimento e sucesso para aquele que se distanciou e se esforça para ampliar esta distância.

\section{Referências}

Abdal, A. \& Navarra, J. (2014). "Uni por Uni, eu escolhi a que era do lado da minha casa": Deslocamentos cotidianos e o acesso, a permanência e a fruição da universidade por bolsistas do ProUni no Ensino Superior privado. Novos estudos - CEBRAP, 99, 65-87.

Aguiar, W. M. J. \& Ozella, S. (2003). O sentido subjetivo atribuído à escolha profissional: Um estudo com jovens de camadas populares. Em S. Ozella (Org.), Adolescências Construídas: a visão da psicologia sócio-histórica (pp. 253-276). São Paulo: Cortez. 
Aguiar, W. M. J. \& Ozella, S. (2006). Núcleos de significação como instrumento para apreensão da constituição dos sentidos. Psicologia Ciência e Profissão, (26), 222-245.

Amaral, D. P \& Oliveira, F. B. (2011). O Prouni e a conclusão do ensino superior: novas trajetórias pessoais e profissionais dos egressos. Em Ensaio: Avaliação e Políticas Públicas em Educação, 19 (73), 861-890, out/dez.

Bock, S. D. (2002). Orientação Profissional: a abordagem sóciohistórica ( $3^{\mathrm{a}}$ ed.). São Paulo: Editora Cortez.

Bock, S. D. (2008). A escolha profissional de sujeitos de baixa renda recém egressos do ensino médio. Tese de Doutorado. Universidade Estadual de Campinas, Campinas.

Gonçalves, M. G. M. \& Bock, A. M. B. (2009). A dimensão subjetiva dos fenômenos sociais. Em A. M. B. Bock \& M. G. M. Gonçalves (Orgs.), A dimensão subjetiva da realidade - uma leitura sóciohistórica (pp.74-116). São Paulo: Editora Cortez.

Gonçalves Filho, J. M. (1998). Humilhação social: um problema político em psicologia. Revista Psicologia USP, 2 (9), 11-67.

González Rey, F. (2005). Pesquisa Qualitativa e Subjetividade: Os processos de construção da informação. São Paulo: Editora Pioneira Thomson Learning.

Instituto Nacional de Estudos e Pesquisas Educacionais Anísio Teixeira [INEP] (2008). Censo da Educação Superior 2008 CENSUP. Recuperado: 15 ago. 2013. Disponível: http://www. portal.inep.gov.br/superior-censo-superior.

Lei n. 11.096, de 13 de janeiro de 2005. (2005). Institui o Programa Universidade para Todos - ProUni: regula a atuação de entidades beneficentes de assistência social no ensino superior, altera a Lei no 10.981, de 9 de julho de 2004, e dá outras providências. Brasília, DF: Diário Oficial da União. Recuperado: 10 fev. 2012. Disponível: http://presidencia.gov.br.

Mongim, A. B. (2015). Crescimento pessoal, mediação e sacrifício: itinerários sociais de estudantes beneficiários do PROUNI. Educação e Sociedade, 36 (133), 927-943.

Programa Universidade para Todos [PronUni] (n.d.). O Programa. Ministério da Educação: ProUni. http://prouniportal.mec.gov.br/. Recuperado: 10 fev. 2012. Disponível: http://prouniportal.mec.gov. br/o-programa.

Oliveira, A. S. (2009). Os sentidos da escolha da profissão, por jovens de baixa renda: um estudo em psicologia sócio-histórica. Dissertação de Mestrado em Educação: Psicologia da Educação, Pontifícia Universidade Católica de São Paulo, São Paulo.

Oliveira, A.S. (2014). A dimensão subjetiva da desigualdade social: um estudo sobre a escolha do curso universitário entre os alunos bolsistas do programa universidade para todos - ProUni. Tese de doutorado em Educação: Psicologia da Educação, Pontifícia Universidade Católica de São Paulo, São Paulo.

Ristoff, D.A. (2011). A expansão da educação superior brasileira: tendências e desafios. Em F. C. P. Paula \& N. F. Lamarra (Orgs.), Reformas e democratização do ensino superior no Brasil e na América Latina (pp. 191-206). Aparecida, São Paulo: Ideias \& Letras,

Saraiva, L. A. S. \& Nunes, A. S. (2011). A efetividade de programas sociais de acesso à educação superior: o caso do Prouni. $A P$ - Rio de Janeiro 45 (4), 941-64. 


\section{Sobre as autoras}

Alessandra dos Santos Oliveira (alessandra.oliveyra@uol.com.br)

Psicóloga, Doutora em Educação: Psicologia da Educação pela Pontifícia Universidade Católica de São Paulo (PUCISP). Atualmente é professora do curso de Psicologia das Faculdades Metropolitanas Unidas (FMUISP).

Ana Mercês Bahia Bock (abock@pucsp.br)

Psicóloga e Doutora em Psicologia Social pela Pontifícia Universidade Católica de São Paulo (PUCISP). Atualmente é professora titular e coordenadora do curso de Pós-Graduação em Educação: Psicologia da Educação da mesma universidade.

Este artigo tem como base a tese de doutorado intitulada "A dimensão subjetiva da desigualdade social: um estudo sobre a escolha do curso universitário entre os alunos bolsistas do Programa Universidade para Todos - ProUni”. A pesquisa foi realizada na Pontifícia Universidade Católica de São Paulo (PUCISP), sob a orientação da Profa. Dra. Ana Mercês Bahia Bock e teve o apoio financeiro da Capes e do CNPq. 